\title{
Diarrhea Associated Costs among Children Less Than 5 Years of Age from Health Care Provider and Social Perspectives in Albania
}

Albana Ahmeti, Artan Simaku, Iria Preza, Silva Bino

Institute of Public Health, Epidemiology and Health Systems, St. Aleksander Moisiu Nr. 80, 1000 Tirana, Albania

\author{
Citation: Ahmeti A, Simaku A, Preza I, Bino S \\ Diarrhea Associated Costs among Children \\ Less Than 5 Years of Age from Health Care \\ Provider and Social Perspectives in Albania. OA \\ Maced J Med Sci. 2013 Dec 15; 1(1):112-116. \\ http://dx.doi.org/10.3889/oamjms.2013.023 \\ Key words: Albania; Diarrhea; Health Care \\ Costs; Primary Care; Social Costs. \\ "Correspondence: Mr. Ervin Toci. Institute of \\ Public Health, Epidemiology and Health \\ Systems, St. Aleksander Moisiu Nr. 80, 1000 \\ Tirana, Albania. Phone: +355694050121 . E- \\ Mail: ervintoci@yahoo.com \\ Received: 29-Sep-2013; Revised: 24-Oct- \\ 2013; Accepted: 20-Nov-2013; Online first: \\ 23-Nov-2013 \\ Copyright: ๑ 2013 Ahmeti A. This is an open- \\ access article distributed under the terms of \\ the Creative Commons Attribution License, \\ which permits unrestricted use, distribution, \\ and reproduction in any medium, provided the \\ original author and source are credited. \\ Competing Interests: The authors have \\ declared that no competing interests exist.
}

\begin{abstract}
Background: Diarrheal diseases count for a considerable proportion of morbidity, mortality and elevated use of health services and costs, especially in developing countries. In limited resource countries like Albania, it is essential to assess the costs associated with diarrhea, from health provider and social perspective, as a first step toward prioritization of interventions.

Materials and Methods: We used the 2011 information by gathering data from primary care, emergency rooms (ER) and hospitals. Average non-medical and medical costs were used. To assess the social costs of diarrhea we interviewed parents of children with diarrhea. Based on this information the total cost of diarrhea in Albania was calculated.

Results: The total mean cost per hospitalized, emergency room and outpatient diarrhea case was $\$ 228.97, \$ 17.68$ and $\$ 9.24$, respectively. The total social costs per each hospitalized, ER and outpatient diarrhea case were $\$ 45.66, \$ 15.22$ and $\$ 15.22$, respectively. The final burden of diarrhea, in terms of costs, in Albania was approximately \$3 million in 2011.

Conclusion: The high burden of diarrhea associated costs for the Albanian health care system finances dictates the necessity to assess the costs of a potential rotavirus immunization program in order to prioritize the interventions based on scientific evidence.
\end{abstract}

\section{Introduction}

Diarrheal diseases represent a major cause of morbidity and mortality worldwide. In developing countries, diarrhea related deaths amount to approximately 2.5 million among children under 5 years of age and about one in five children of this age die due to diarrheal causes in these regions [1]. Rotavirus disease is responsible for a good proportion of diarrheal cases in developed and developing countries being responsible for about $6 \%$ of such episodes and one in five cases of diarrheal associated deaths in children fewer than five years of age [2]. It is reported that up to $27 \%$ of hospitalizations associated with diarrhea are caused by rotavirus [3]. In addition, another study reported that the prevalence of rotavirus among diarrheal cases was $36 \%$ in Mexico [4]. By age five, every child will have an episode of diarrhea, one in five will see a family doctor, one in 65 will be hospitalized and one in 293 children will die due to rotavirus disease. Furthermore, four in five deaths attributed to rotavirus occur in the less developed world [5].

Diarrheal diseases are associated with a considerable use of health care services and costs (38). In USA, the annual rates of hospitalization due to diarrheal diseases range from 35 per 10 thousand children under 5 years of age $[4 \%$ of all hospitalizations for these age-group] [6] to 97 cases per 10 thousand children [3] whereas approximately one in ten outpatient visits involved diarrheal diseases [ $2 \%$ of all outpatient visits] [6]. The median cost of treating a diarrhea and rotavirus diarrhea case in hospital was $\$ 2307$ and $\$ 2303$, respectively, in USA in 1998 [6]. In Mexico, the cost of treating one hospitalized rotavirus diarrhea case was 936 US\$ and in total around 6 million US\$ were spent during 2004 
for hospital services related to this disease [4]. In Vietnam, the total cost of rotavirus disease treatment was $\$ 5.3$ million in 2004 which comprised of $\$ 3.1$ million direct medical costs, $\$ 0.7$ million direct nonmedical costs and $\$ 1.5$ million indirect costs [7]. In Colombia, diarrhea also constituted a heavy burden for the economy and health system of the country as well [8].

It is clear that diarrhea costs pose a heavy burden upon health finances of a country, especially for the developing ones. In Albania, the financing of the health system is low. For example, in 2011, the total health expenditure was $5.06 \%$ of GDP: public health expenditure accounting for $2.68 \%$, private sector $2.32 \%$ and foreign resources $0.06 \%$ [9]. When system resources are limited, as with the case of Albania, one has to prioritize among the array of interventions needed to take place. In the case of diarrhea, it is important to now the actual total expenditure incurred for treating this condition against the potential benefits of preventing it through a vaccination program.

In this context, our aim was to assess the cost of treating diarrhea in the public system from the health service providers and social perspective.

\section{Methods}

The cost of diarrheal disease was assessed from the health care provider and social perspectives.

To assess the diarrhea health care costs, we collected data in the three levels of care: hospital level, emergency rooms (ER) and primary health care system (referred hereafter as "out-patient visits") in 2011. Information was retrieved from the tertiary University Hospital Center "Mother Tereza" (UHCT) in Tirana and health care facilities of Lezha, Durres, Fier and Vlora. In hospitals we included diarrhea cases of any nature comprising bacterial, viral, and parasitic or diarrhea of unknown etiology, corresponding to ICD-9 codes 001-007.9, 008.6-008.61, 009 and 787.91.

The calculation of health care costs of diarrhea was based on average figures because Albania does not have a DRG system in place. The only calculation of cost which used a sample of patients regarded the calculation of "direct diarrheaspecific treatment cost" based on a sample of medical records from pediatric infectious disease ward in UHCT. The cost of a hospitalized diarrhea case was calculated like this: first, all the non-treatment expenditures from pediatric infectious disease wards of 5 hospitals under study were retrieved from the financial office of these hospitals. This sum was divided by the total number of hospitalization days occurred in these pediatric wards. By dividing the total non-medical cost by the total number of hospital days in pediatric wards we found the average non-medical cost was per each day of hospitalization. Then, the direct medical cost of diarrhea was calculated based on a sample of 169 medical records of UHC in Tirana and the resulting average medical cost was then added to the average non-medical cost to yield the total average cost (medical and non-medical) per one hospitalized diarrhea case in Albania.

Following similar approach, i.e. basing of average numbers, we calculated the average cost of one ER and outpatient diarrhea case. In the emergency room, we asked the doctors about the most frequent medication schemes used in ER pediatric patients and then added this average figure to the average non-medical cost incurred in ER.

To calculate the cost of an outpatient diarrhea case, we retrieved information about medical costs by asking 41 family physicians, found an average (a minimum and a maximum) and then added this to the average non-medical cost incurred in outpatient settings.

For calculating the diarrhea associated social costs, we interviewed the parents of children with diarrhea in the respective health care facilities in these 5 districts. We asked them about the amount of time they lost by caring after their child (days of hospital stay if the child has been hospitalized) and the respective values in us dollars were then calculated based on GDP estimations for Albania, as will be explained later. Also, information on the distance from their home to the health facility and the amount of money spent for transportation purposes was collected.

The Albanian gross domestic product (GDP) was $\$ 3,707 /$ capita in 2010 [10]. This GDP value was used in our models to calculate the diarrhea associated costs in 2011.

The financial burden of diarrhea to the health care system was assessed by determining the number of each event associated with diarrhea disease (such as hospitalization, emergency room visit, outpatient visit, etc.) and retrieving information on the cost of each event. Information regarding various procedures and their related costs in UHCT, district regional hospitals, ERS and health care facilities was obtained by interviewing the medical staff and the directors and managers of these facilities as well as by consulting with the information from the health insurance institute (HII). The information on specific diarrhea treatments or diagnostic tests was retrieved from the medical records. Information was collected on every aspect which could play a role in the cost of a diarrhea case: examination and diagnostic tests performed, the length of stay, medication and costs of the visit including the costs for facilities and medical personnel. The appropriate indicators were applied to calculate the cost of a diarrhea case managed in health centers as well (excluding the length of stay since these were outpatient visits).

In general, health care costs associated with 
diarrhea include: a) direct medical and non-medical costs; and, b) indirect costs, which comprise of social and transportation costs.

\section{Calculation of health care costs of diarrhea}

The health care costs of severe diarrhea incurred at hospital, ER and primary health care levels were calculated as follows:

A) hospital costs of diarrhea cases, which are treated only in pediatric infectious disease wards, include:

i) direct medical cost of diarrhea (excluding treatment). This was calculated by averaging the data from the 5 hospitals in our study, and includes: medical staff salary and costs of diagnostic tests, food, and consumable materials.

ii) direct diarrhea-specific treatment cost. This was assessed by collecting data from a random sample of medical records $(n=169)$ among all diarrhea cases $(n=1002)$ admitted to UHCT between januarydecember 2011.

iii) direct non-medical costs were calculated based on the information from cost units of the pediatric wards of respective hospitals and HIl's department of economy. These include: a) utility costs (electricity, water, heating, and telephone); b) cleaning; c) laundry; d) administration; e) maintenance and depreciation costs.

The fraction of total hospital beds allocated to the infectious disease wards (around 3.2\%) was used to estimate the direct non-medical costs attributed to the pediatric infectious disease ward during one year. To estimate the inpatient cost per bed per day, the total costs, by summing the direct medical and nonmedical cost as described above, were divided by the total number of beds. The information on the total number of bed days in a given year was taken from the HII. Finally, the inpatient cost per bed/day was multiplied by the average length of stay (los) in days to estimate the average cost of hospitalization for each severe diarrhea case (or event).

B) emergency room costs of diarrhea cases - the number of diarrhea outpatient visits to the ER was determined from the ER registry of the UHCT and four regional hospitals. Based on ER registries and interviews with the ER personnel it was possible to ascertain the procedures performed on each diarrheal case and the average length of visit for a diarrhea case presented at the ER of these public hospitals. The cost per visit includes the direct costs such as: the salaries of the physician and nurses, cost of perfusions, prescriptions and indirect costs such as; electricity, water and maintenance.

C) outpatient costs of diarrhea cases - the cost of an outpatient diarrhea case visit was based on the information retrieved by the interviews with 41 family physicians in the 5 districts included in the study, which took place between July-August 2012. The cost of the visit includes the wage of pediatric and medical staff and other costs estimated by the respective health centers $(\mathrm{HC})$. The estimation of the treatment cost is based on the "prices of drugs" list [11] and the prescription of treatment of a diarrhea case given by the pediatricians or family doctors in the $\mathrm{HC}$.

\section{Calculation of social costs of diarrhea.}

Social costs are related to the indirect societal costs in the form of productivity loss as a result of caretakers taking time off work. We didn't have the data about the median wage for rural and urban areas but we had the information on the minimum wage which is determined by the decision of council of ministers. Under these circumstances we used the WHO guidelines for the standardization of economic evaluation of immunization programs as the most appropriate approach to estimate the loss of productivity by using GDP for hospitalization cases. The 2010 GDP figure enabled the estimation of the lost time. The average length of stay of hospitalized diarrhea cases is estimated to be 3 days and 1 day for outpatient cases. The 2010 GDP per region is divided by number of working days per year (266 days) multiplied by 3 days for all cases admitted to the hospital, and multiplied by 1 day for all ER cases.

Also, the transportation cost, as an indirect non-medical cost, was included in the social cost as well. This implies the amount of money caretakers from rural areas, suburban areas and other cities need to spend to reach the health center, ER or hospital. To calculate the amount of money needed we used the official directives of the decision of council of ministers regarding "the price and transport fees". Here we implied that all caretakers and diarrhea cases get to the hospital through the public transportation. Hence, the transportation cost calculation excluded the cases when caretakers used a taxi or personal car. The mean transport costs (twoway travelling), for the six regions were calculated.

\section{Results}

We collected financial information for children with diarrhea who showed up for treatment either in health centers, secondary/tertiary hospitals or emergency rooms. Table 1 presents an array of health care and social costs per diarrhea case managed and treated in these health care facilities. The cost of a diarrhea hospital bed per day varied from $\$ 31$ to $\$ 112$ with a mean value of $\$ 73.2$. The cost of treatment per hospitalized diarrhea case varied from $\$ 1.8$ to $\$ 56.96$ (mean value 3.12 US\$/day). Taking into account that on average every diarrhea case is hospitalized for 3 days, and then the total 
mean cost for a hospitalized diarrhea case amounts to approximately $\$ 228.97$.

Table 1: Mean values of direct and indirect costs of diarrhea disease by the level of health care.

\begin{tabular}{|c|c|c|c|}
\hline Level of care, type of cost & $\begin{array}{l}\text { USD } \\
\text { Mean } \\
\text { value }\end{array}$ & $\begin{array}{c}\text { USD } \\
\text { Min } \\
\text { value }\end{array}$ & $\begin{array}{c}\text { USD } \\
\text { Max } \\
\text { value }\end{array}$ \\
\hline \multicolumn{4}{|l|}{ Hospital } \\
\hline Cost of bed/day (excluding treatment) & $73.20^{\dagger}$ & 30.83 & 112.00 \\
\hline Cost of treatment/hospitalized case & 3.12 & 3.12 & 3.12 \\
\hline Length of stay/hospitalized case & 3 & 3 & 3 \\
\hline $\begin{array}{l}\text { (number of days) } \\
\text { Total inpatient diarrhea cost per case }\end{array}$ & 228.97 & 101.85 & 345.36 \\
\hline \multicolumn{4}{|l|}{ Emergency Room (ER) } \\
\hline Cost of ER diarrhea visit per case & 17.68 & 13.69 & 31.88 \\
\hline \multicolumn{4}{|l|}{ Outpatient } \\
\hline $\begin{array}{l}\text { Cost of } \mathrm{HC} \text { diarrhea visit per case } \\
\text { Socts }\end{array}$ & 9.24 & 7.9 & 14.6 \\
\hline \multicolumn{4}{|l|}{$\begin{array}{l}\text { Social costs } \\
\text { Cost of transportation/day }\end{array}$} \\
\hline Cost of loss productivity/day per & 1.46 & 0.6 & \\
\hline hospitalized case & 13.76 & 9.42 & 22.38 \\
\hline $\begin{array}{l}\text { Total days lost per hospitalized case } \\
\text { Total days lost per ER and outpatient }\end{array}$ & 3 & 3 & 3 \\
\hline $\begin{array}{l}\text { Total days lost per ER and outpatient } \\
\text { case }\end{array}$ & 1 & 1 & 1 \\
\hline Total social cost per hospitalized & $\begin{array}{l}45.66 \\
1522\end{array}$ & $\begin{array}{c}30.6 \\
10.02\end{array}$ & $\begin{array}{r}121.14 \\
40.38\end{array}$ \\
\hline case & 15.22 & 10.02 & 40.38 \\
\hline Total social cost per ER case & 15.22 & & \\
\hline \multicolumn{4}{|l|}{ Total social cost per outpatient case } \\
\hline
\end{tabular}

The cost of an emergency room visit due to diarrhea was $\$ 17.68$ whereas the cost of an outpatient visit due to diarrhea was $\$ 9.24$ (Table 1).

Regarding the social costs of diarrhea, on average people spent $\$ 1.46$ a day for public transportation whereas each day off work due to diarrhea costs about $\$ 13.76$. Since on average for each inpatient diarrhea case caretakers lose 3 days of work and for each er and outpatient diarrhea case they lose one day of work, then the total social costs per each hospitalized, er and outpatient diarrhea case were $\$ 45.66, \$ 15.22$ and $\$ 15.22$, respectively (Table $1)$.

Based on nationally reported hospitalizations for diarrhea in children $<5$ years old, there were 7,500 cases of diarrhea which were treated in country's hospitals in 2011. The five hospitals included in this study covered 5,204 diarrhea cases in 2011 or $69 \%$ of total hospitalized diarrhea cases in the country.

Outpatients' visits encompass visits at primary health care facilities in urban and rural area and hospital emergency room visits. A total of 27,029 outpatient visits for diarrhea in children $<5$ years old were reported in 2011 from the syndromic surveillance system which consists of weekly mandatory reporting of the infectious syndrome "diarrhea without blood". From the total of 27,029 outpatient visits, $40 \%$ of them $(n=10,812)$ were performed in ERs (secondary health care level) and $60 \%(n=16,217)$ in the health centers (primary health care).

Taking into account these figures, the health care level and total costs of diarrhea in Albania in 2011 are presented in Table 2. The total hospital expenditure due to treatment of diarrhea was approximately 1.7 million US\$ in 2011 . The total amount of money spent on diarrhea in ERS was around $\$ 200,000$ and $\$ 150,000$ more dollars were spent in outpatient visits associated with diarrhea. The total social cost of diarrhea was around 750,000 US $\$$ making the final burden of diarrhea in Albania approximately $\$ 3$ million in 2011 (Table 2).

Table 2: Total diarrhea associated costs in Albania, 2011.

\begin{tabular}{lccc}
\hline Level of care, type of cost & $\begin{array}{c}\text { USD } \\
\text { Mean } \\
\text { value }\end{array}$ & $\begin{array}{c}\text { Number of } \\
\text { cases/year }\end{array}$ & $\begin{array}{c}\text { Total } \\
\text { expenditure (in } \\
\text { USD) }\end{array}$ \\
\hline $\begin{array}{l}\text { Hospital } \\
\quad \text { Inpatient cost/hospitalized } \\
\text { case }\end{array}$ & 228.97 & 7,500 & $\$ 1,717,275$ \\
$\begin{array}{l}\text { Emergency Room (ER) } \\
\quad \text { Cost of ER visit }\end{array}$ & 17.68 & 10,812 & $\$ 191,156$ \\
$\begin{array}{l}\text { Outpatient } \\
\quad \text { Cost of outpatient visit }\end{array}$ & 9.24 & 16,217 & $\$ 149,845$ \\
$\begin{array}{l}\text { Social costs } \\
\quad \text { Total social cost per } \\
\text { hospitalized case }\end{array}$ & 45.66 & 7,500 & $\$ 342,450$ \\
$\quad \begin{array}{l}\text { Total social cost per ER } \\
\text { case }\end{array}$ & 15.22 & 10,812 & $\$ 164,559$ \\
$\quad \begin{array}{l}\text { Total social cost per } \\
\text { outpatient case }\end{array}$ & 15.22 & 16,217 & $\$ 246,823$ \\
TOTAL COST OF DIARRHEA & & & \\
\hline
\end{tabular}

\section{Discussion}

This study provided information on the burden and costs of treatment of severe diarrhea cases in Albania in 2011. To our knowledge, no other study has reported such data for this country. We used the information collected from some of the major tertiary and secondary hospitals in the country over a oneyear period, together with financial data offered by hospitals' economic units, HII as well as health care facilities' medical staff. Furthermore, besides interviewing the parents of diarrhea children treated in these facilities to retrieve information about the cost of transportation and leaving work due to the disease, we used national data on GDP and minimum wage in order to estimate the social costs related to diarrhea treatment in different health care settings.

In total, there were around 35,000 cases of diarrhea treated either in hospital settings or emergency rooms/primary health care centers in Albania in 2011. The amount of money spent on diarrhea treatment on different levels of the health care system totalled about $\$ 3$ million, which comprises a substantial burden to the health finances of this middle income country.

Our study referred to children aged 5 years or younger who suffered diarrhea. The costs of diarrhea treatment for these children (around \$2 million) are totally covered by the public sector. However, diarrhea also causes social costs which amount to almost $\$ 800,000$, the overwhelming part of which occurs in terms of loss of productivity. We calculated the average cost of transportation referring to the public transportation rates only. Nevertheless, it is very likely that these figures are underestimated because very often parents turn to private transport for bringing their sick children to the respective health care facilities, 
especially in emergency cases.

In our study, the average length of stay for diarrhea associated hospitalizations was 3 days whereas a US study reported a median length of 2 days in 1993-1996 [6] whereas another study reported an average stay of 3-4 days [12]. The total direct costs of diarrhea in children under the age of 5 years in Albania are higher compared to that of other developing countries. For example, Fischer et al. Reported that the total direct costs of diarrhea in children younger than 5 years in Vietnam were approximately \$4 million in 2004 [7], but the population of Vietnam is around 25 times higher than that of Albania. In Uzbekistan, the hospitalization cost of a diarrhea case was about $\$ 77.8$ in 2004 [13] whereas we report an average hospitalization cost of $\$ 229$ per case. However, costs associated with diarrhea are obviously lower compared to developed countries such as US [12] and Australia [14], where costs per hospitalized diarrhea case amount to several thousand dollars. It is obvious that the direct costs of diarrhea vary according to country's level of development and the type of health system it applies. For example, in Asia the medical costs of diarrhea are different for low income (\$29 million), middle (\$114 million) and high income countries (\$46 million) [15].

Given the burden of diarrhea associated costs for the Albanian health care system finances, maybe there is time to take into consideration the introduction of the rotavirus immunization program in this country. As suggested in the literature, rotavirus is a very common cause of severe diarrhea and hospitalization for children under age of five in developed $[12,14,16]$ and developing countries [4]. Numerous studies have shown that rotavirus immunization programs might be cost-effective, even though many aspects have to be taken into consideration such as morbidity and mortality rates due to rotavirus and vaccine price [7, $12,13,15]$. Besides the actual costs of diarrhea, these very important aspects related to rotavirus immunization should be investigated through carefully designed future studies, in order to help the decision makers to opt for a vaccination program or other potential interventions.

Our study has several limitations. First, we relied on average data from included hospitals in order to calculate the non-medical cost of a hospital diarrhea case in Albania due to the inability to find accurate data. Furthermore, the calculation of cost of a diarrhea case in the emergency room and outpatient settings has also relied on average numbers collected by asking the physicians about treatment and retrieving information from financial offices of hospitals. This could have led to serious deviations from the true costs. Second, we didn't have information regarding the type of diarrhea included in our survey as most medical records were incomplete in this regard. Therefore, the assumption that a considerable number of diarrhea cases are caused by rotavirus is based solely on the international literature suggestions. As a result, our recommendation calling for a comparison of actual situation versus the cost of a vaccination program warrants caution.

\section{References}

1. Kosek M, Bern C, Guerrant RL. The Global Burden Of Diarrhoeal Disease, As Estimated From Studies Published Between 1992 And 2000. Bull World Health Organ. 2003; 81(3):197-204.

2. De Zoysa I, Feachem RG. Interventions For The Control Of Diarrheal Disease Among Young Children: Rotavirus And Cholera Immunization. Bull World Health Organ. 1985; 63:569-83.

3. Jin S, Kilgore PE, Holman RC, Clarke MJ, Gangarosa EJ, Glass RI. Trends In Hospitalizations For Diarrhea In United States Children From 1979 Through 1992: Estimates Of The Morbidity Associated With Rotavirus. Pediatr Infect Dis J. 1996; 15(5):397404.

4. Granados-García V, Velázquez-Castillo R, Garduño-Espinosa J, Torres-López J, Muñoz-Hernández $\mathrm{O}$. Resource Utilization And Costs Of Treating Severe Rotavirus Diarrhea In Young Mexican Children From The Health Care Provider Perspective. Rev Invest Clin. 2009; 61(1):18-25.

5. Parashar UD, Hummelman EG, Bresee JS, Miller MA, Glass RI. Global Illness And Deaths Caused By Rotavirus Disease In Children. Emerg Infect Dis. 2003; 9(5):565-72.

6. Zimmerman CM, Bresee JS, Parashar UD, Riggs TL, Holman RC, Glass RI. Cost Of Diarrhea-Associated Hospitalizations And Outpatient Visits In An Insured Population Of Young Children In The United States. Pediatr Infect Dis J. 2001; 20(1):14-9.

7. Fischer TK, Anh DD, Antil L, Cat ND, Kilgore PE, Thiem VD, Rheingans R, Tho Le H, Glass RI, Bresee JS. Health Care Costs Of Diarrheal Disease And Estimates Of The Cost-Effectiveness Of Rotavirus Vaccination In Vietnam. J Infect Dis. 2005; 192(10):17206 .

8. Alvis-Guzman N, Orozco-Africano J, Paternina-Caicedo A, Coronell-Rodríguez W, Alvis-Estrada L, Jervis-Jálabe D, De La Hoz-Restrepo F. Treatment Costs Of Diarrheal Disease And AllCause Pneumonia Among Children Under-5 Years Of Age In Colombia. Vaccine. 2013; 31( Suppl 3):C58-62.

9. Department Of Economy, Ministry Of Health, Tirana, Albania 2011 [In Albanian].

10. Decision of the Council of Ministers Nr. 748, Datë 2.11.2011 "Për Një Ndryshim Në Vendimin Nr. 69, Datë 02.02.2011 Të Këshillit Të Ministrave "Për Miratimin E Kuadrit Makroekonomik E Fiskal Për Periudhën 2012-2014", Të Ndryshuar. [In Albanian].

11. Institute Of Statistics, Tirana, Albania.

12. Tucker AW, Haddix AC, Bresee JS, Holman RC, Parashar UD, Glass RI. Cost-Effectiveness Analysis of a Rotavirus Immunization Program for the United States. JAMA. 1998; 279:1371-6.

13. Isakbaeva $E T$, Musabaev E, Antil L, Rheingans R, Juraev R, Glass RI, Bresee JS. Rotavirus Disease In Uzbekistan: CostEffectiveness Of A New Vaccine. Vaccine. 2007; 25(2):373-80.

14. Carlin JB, Jackson T, Lane L, Bishop RF, Barnes GL. Cost Effectiveness Of Rotavirus Vaccination In Australia. Austr N Z J Public Health. 1999; 23:611-6.

15. Podewils LJ, Antil L, Hummelman E, Bresee JS, Parashar UD, Rheingans R. Projected Cost-Effectiveness Of Rotavirus Vaccination For Children In Asia. J Infect Dis. 2005; 192(Suppl 1):S133-45.

16. Soriano-Gabarró M, Mrukowicz J, Vesikari T, Verstraeten T.) Burden Of Rotavirus Disease In European Union Countries. Pediatr Infect Dis J. 2006; 25(1 Suppl):S7-S11. 